\title{
Comparison between multi-spot laser and conventional laser in treatment of diabetic clinically significant macular edema
}

\author{
Comparação entre laser multi-spot e laser convencional \\ no tratamento de edema macular diabético
}

Kareem Mohsen Elsawah, Amin Faisal El-Ikwa, Ghada Zein El-Abedin, Marwa Aly Zaky ${ }^{1}$

\begin{abstract}
Objectives: The purpose of this work is to assess the safety and the efficacy of multi-spot laser in comparison with the conventional laser in the treatment of non-proliferative diabetic retinopathy with CSME in relation to the visual outcome, central macular thickness by (OCT) and the presence of adverse events. Methods: prospective randomized study on total number of 50 eyes divided in two groups each one 25 patients . group A patients underwent focal, grid laser or modified grid macular laser photocoagulation using green laser $532 n m$ GYC1000. Group B underwent focal, grid laser or modified grid macular laser photocoagulation multispot laser photocoagulation (VALON $T T$ inclusion criteria was diabetes mellitus type II patients, clinically significant macular edema . patients were monitored by BCVA, OCT, IOP, adverse events pre and 1 week, one month, three months postoperative. Results: The mean preoperative BCVA in group $A$ with conventional laser was $0.294 \pm 0.1715$ decimal and in group B with multispot laser (valon) was $0.3040 \pm 0.2140$. The mean BCVA 3 months post-laser in group $A$ was $0.4820 \pm 0.244$ decimal and in Group B was $0.5080 \pm 0.1977$. Central macular thickness of the patients was measured pre-laser and in the follow up periods of 1week, one month, three months. The mean preoperative CMT in Group A was 375.92 \pm 65.69 um and in Group B was 361.0 \pm 50.400 um. The mean CMT 3 months post-laser in Group A was $314.44 \pm 85.938$ um and in Group $B$ was $0322.668 \pm 57.500 \mathrm{um}$. The multisport system parameters used higher power of mean $155 \mathrm{~mW} \pm 90.1$ more than the conventional laser $100 \mathrm{~mW} \pm 19.4$ to produce the same therapeutic visible effect. Conclusion: We found that multisport system is safe, rapid, effective in treatment of clinically significant macular edema in short term follow up periods and had short exposure time. Although the shorter pulse duration of the multisport system necessitates the use of a higher power, it is not associated with adverse effects.
\end{abstract}

Keywords: Laser; Macular edema; Diabetic retinopathy

\section{RESUMO}

\begin{abstract}
Objetivos: O objetivo deste trabalho é avaliar a segurança e a eficácia do laser multi-spot em comparação com o laser convencional no tratamento da retinopatia diabética não proliferativa com CSME em relação ao resultado visual, à espessura macular central por (OCT) e à presença de eventos adversos. Métodos: estudo prospectivo randomizado sobre o número total de 50 olhos divididos em dois grupos, cada um de 25 pacientes. Os pacientes do grupo A foram submetidos a fotocoagulação focal, a laser de grade, ou de laser macular de grade modificada com a utilização do laser verde de 532nm GYC-1000. O grupo B foi submetido a fotocoagulação fotocoagulação focal, a laser de grade, ou de laser macular de grade modificada (os critérios de inclusão VALON TT foram pacientes com diabetes mellitus tipo II, edema macular clinicamente significativo). Os pacientes foram monitoradoss para BCVA, OCT, IOP, eventos adversos pré e uma semana, um mês, e três meses de pós-operatório. Resultados: O BCVA preoperatório médio no grupo A com laser convencional foi 0,294 \pm 0,1715 decimal, e no grupo B com laser multispot (valon) foi 0,3040 \pm 0,2140. O BCVA médio 3 meses após o laser no grupo A foi $0.4820 \pm 0.244$ decimal, e no grupo B foi $0.5080 \pm 0.1977$. A espessura macular central dos pacientes foi medida antes do laser e nos períodos de acompanhamento de 1 semana, um mês e três meses. O CMT médio pré-operatório no grupo A foi 375,92 \pm 65,69 um, e no grupo B foi 361,0 \pm 50,400 um. O CMT médio 3 meses após o laser no grupo A foi 314,44 $\pm 85,938$ um, e no grupo B foi 0322,668 \pm 57,500 um. Os parâmetros do sistema multisport utilizaram uma potência media $155 \mathrm{~mW} \pm 90,1$ superior a do laser convencional de $100 \mathrm{~mW} \pm 19,4$ para produzir o mesmo efeito terapêutico visível. Conclusão: Descobrimos que o sistema multisport é seguro, rápido e eficaz no tratamento de edema macular clinicamente significativo em períodos de acompanhamento de curto prazo, e ele teve um curto tempo de exposição. Embora uma duração de pulso mais curta do sistema multisport necessite utilizar uma potência maior, ela não está associada aos efeitos adversos.
\end{abstract}

Descritores: Laser; Edema Macular; Retinopatia diabética

Research Institute of Ophthalmology, Egipt.

The authors declare no conflicts of interests.

Received for publication 14/10/2016 - Accepted for publication 03/12/2016.

Rev Bras Oftalmol. 2017; 76 (4): 175-80 


\section{INTRODUCTION}

$\mathbf{L}$ aser photocoagulation remains the second-most common eye procedure after cataract extraction, and yet little has changed in laser design over the last 35 years until recently. There are different colors, different laser sources and connecting cables, but otherwise the same single spot delivery system coupled to a slit lamp controlled by a joy stick is still in use. ${ }^{(1)}$

The Early Treatment Diabetic Retinopathy Study (ETDRS) was a landmark trial that firmly established laser photocoagulation as one of the treatments for diabetic maculopathy. The study showed that for eyes with clinically significant macular oedema (CSMO), the rate of moderate visual loss [a doubling of the visual angle (15 or more letter loss on ETDRS charts)] was reduced from $24 \%$ to $12 \%$ at 3 years. CSMO was defined as one or more of the following:

1. Retinal thickening at or within $500 \mu \mathrm{m}$ of the center of the macula

2. Hard exudates at or within $500 \mu \mathrm{m}$ of the center of the macula if associated with adjacent retinal thickening.

3. An area or areas of retinal thickening one disc area in size, at least part of which is within one disc diameter of the fovea. ${ }^{(2)}$

Conventional photocoagulation using a single application of laser energy per shot is usually delivered as a 100-200 ms duration burn. This gets difficult for the patients and the treating doctors and takes a long time especially in pan retinal photocoagulation (PRP) 1

The advent of multiple spot lasers, such as the Vitra Multispot (532 nm Green ND:YAG, Quantel Medical) or the Supra Scan 577 (577 nm yellow multispot or micro pulse, Quantel Medical), has changed the face of laser photocoagulation, making it possibly safer, easier, and more effective. (3)

The efficacy of multispot lasers can be attributed to several changes that have been made in the treatment parameters for multispot lasers as compared with treatment parameters for conventional lasers. The exposure time to the laser has been reduced and the laser's power increased. The duration of laser treatment has been reduced from $100 \mathrm{~ms}$ to $10 \mathrm{~ms}$ to $20 \mathrm{~ms}$. Once the laser duration is defined, the power of the laser can then be titrated from $200 \mathrm{~mW}$ to higher than $600 \mathrm{~mW}$. Decreased duration of exposure and increased laser power result in better localization of the laser to the external retina and a reduction in thermal diffusion, which reduces the amount of epithelial scarring, scotoma, and inflammation associated with laser. ${ }^{(4-6)}$

But as the type of damage mechanism to retinal pigment epithelium (RPE), other retinal layers and choroid depends on the duration of the applied laser pulse. At continuous wave (CW) to 10-ms exposure time, a pure thermal denaturation of tissue has been shown to be the primary retinal damage mechanism. ${ }^{(7)}$ While from microsecond to nanosecond exposure times, there is evidence that RPE damage is induced by intracellular microbubble formation around the strongly absorbent melanosomes inside the RPE cell. ${ }^{\left({ }^{3}\right)}$ The microbubble formation leads to a disintegration of the RPE cell structure and a disruption of the cell membrane. At subnanosecond exposures, other nonlinear damage mechanisms appear, such as shock-waves and laser-induced breakdown. ${ }^{(9)}$

Multispot laser is also less painful for the patient, as thermal diffusion in the choroid, where pain receptors reside, has been reduced. Multispot laser allows spots to be delivered almost simultaneously and with greater regularity than conventional treatment. The spots are delivered in a $3 \times 3$ or $4 \times 4$ matrixes, allowing more spots to be delivered in a shorter period of time, thus reducing the total time of treatment. ${ }^{(4)}$

One of the studies in 2011, found that The PASCAL photocoagulator (one of multispot lasers ) is safe, rapid, effective in panretinal photocoagulation for proliferative diabetic retinopathy and macular grid photocoagulation for macular edema with rapid learning and had short exposure time. Although the shorter pulse duration of the Pascal necessitates the use of a higher power, it is not associated with adverse effects. ${ }^{(10)}$

\section{Methods}

This study is a prospective and randomized. It was carried out on diabetic patients who came to "Research Institute of Ophthalmology in Giza" between February 2015 till December 2015.

\section{Patient selection}

A total of 50 eyes divided into two groups we took the even number patients like 2,4,6 for Group A and the odd number for Group B :

1- Group A - patients underwent focal, grid laser or modified grid macular laser photocoagulation for diabetic clinically significant macular edema using conventional laser (green laser 532nm GYC-1000) .treatment durations: 50 to 100 $\mathrm{ms}$, spot size from $50 \mathrm{um}$ up to $100 \mathrm{um}$ and power from $50 \mathrm{~mW}$ up to $300 \mathrm{~mW}$.

2- Group B - patients undergoing focal, grid laser or modified grid macular laser photocoagulation for NPDR using multispot laser photocoagulation the multisport laser system (VALON TT) is a $532 \mathrm{~nm}$ frequency-doubled (Nd:YAG) solid-state laser . Durations: 10 to $20 \mathrm{~ms}$, spot size from 50 um up to $200 \mathrm{um}$ and power from $50 \mathrm{~mW}$ up to $300 \mathrm{~mW}$.

\section{Inclusion criteria}

- patients with diabetes mellitus type 2;

- visual acuity decimal equivalent of 0.1 or better;

- newly diagnosed SNPDR (severe nonprolifertive diabetic retinopathy);

- mean central retinal thickness (CRT) of not more than $500 \mathrm{um}$ as measured by optical coherence tomography (OCT) scans;

- adequate pupil dilatation and clear media to perform laser photocoagulation and OCT.

\section{Exclusion criteria:}

- planned PRP within 6 months;

- previous retinal treatment: laser or surgery;

- any previous ocular condition that may be associated with a risk of macular edema like epiretinal membrane, vein occlusion, uveitis , etc. ...);

- uncontrolled hypertension, renal failure, and mental illness;

- poor glycemic control;

- planned intraocular surgery within 6 months.

\section{Pre-laser evaluation}

All participants received detailed ophthalmic examinations:

- Duration of diabetes mellitus, average fasting blood glucose 2 weeks before laser photocoagulation therapy, and recent glycosylated hemoglobin level within 3 months.

- Best corrected visual acuity (BCVA)

- slit lamp examination including dilated fundus examination Fundus flourescin angiography and OCT macula.

Post-laser evaluation

All the patients were examined on the first day after laser by: 
- Slit-lamp examination with dilated fundus examination

- Applanation tonometry

Then all the patients were re-examined one week, one month, three months after laser including the following:

- BCVA

- Applanation tonometry

- Slit lamp examination with Dilated fundus examination

- OCT

\section{Statistical analysis}

Statistical analysis was done using IBM SPSS v 20 (IBM Corp., NY,USA). Descriptive statistics was calculated and the data was summarized as mean $\pm \mathrm{SD}$, and frequencies were reported with numbers and percentages. Multiple variable line graphs were used to compare the Data across visits. Comparisons between numerical data from the different visits were done using repeated measures ANOVA, while comparisons for categorical data were done using Chi square test or Fisher's exact test. The results were considered statistically significant with a $\mathrm{p}$-value $\leq 0.05$

\section{RESULTS}

The study included 50 eyes of 44 patients, 25(50\%) males and $25(50 \%)$ females, 6 patients had both eyes done, with a mean age of 57.72+/-9.08 for group a (Argon) and mean age of 55.52+/6.84 for group B (Valon) (Table 1).

Table 1

Age description

\begin{tabular}{|c|c|c|c|c|c|}
\hline & $\mathbf{N}$ & Minimum & Maximum & Mean & $\begin{array}{c}\text { Std. } \\
\text { Deviation }\end{array}$ \\
\hline Group A & 25 & 39 & 72 & 57.7200 & 9.080 \\
\hline Age & & & & & \\
\hline Group B & 25 & 45 & 70 & 55.5200 & 6.8442 \\
\hline
\end{tabular}

The average laser power, number of burns and mean CMT and follow-up periods for the whole of groups are listed in table 2.

The results were compared in terms of efficacy including central macular thickness (CMT) and visual acuity (VA), power requirement, adverse events.

Table 2

Differences between pre and post VA, laser parameters in each group

\begin{tabular}{lcc}
\hline & Group A & Group B \\
\hline Number of eyes & 25 & 25 \\
Pre-laser VA, mean (SD) & $0.294( \pm 0.171)$ & $0.304( \pm 0.214)$ \\
Post-laser VA 3 months, mean & $0.482( \pm 0.244)$ & $0.508( \pm 0.197)$ \\
Power (mW) , mean (SD) & $110( \pm 19.4)$ & $155( \pm 90.1)$ \\
Number of burns , mean (SD) & $80( \pm 70.4)$ & $150( \pm 88.3)$ \\
\hline
\end{tabular}

\section{Visual acuity}

The visual acuity of the patients was measured pre-laser and in the follow up periods of 1 week, one month, three months. The mean preoperative BCVA in Group A with conventional laser was $0.294 \pm 0.1715$ decimal and in Group B with multispot laser (valon )was $0.3040 \pm 0.2140$. The mean BCVA 3 months post-laser in Group A was $0.4820 \pm 0.244$ decimal and in Group $\mathrm{B}$ was $0.5080 \pm 0.1977$
Table 3

Table showing change in mean visual acuity in different follow up periods

\begin{tabular}{lclccc}
\hline Period & N & Group & Mean & SD & P value \\
\hline Pre-laser & 25 & Group A & 0.2940 & 0.17159 & 0.856 \\
& 25 & Group B & 0.3040 & 0.21405 & \\
One week & 25 & Group A & 0.3320 & 0.18590 & 0.883 \\
post laser & 25 & Group B & 0.3400 & 0.19526 & \\
One month & 25 & Group A & 0.4180 & 0.2299 & 0.515 \\
post laser & 25 & Group B & 0.4600 & 0.2222 & \\
Three months & 25 & Group A & 0.4820 & 0.24405 & 0.681 \\
post laser & 25 & Group B & 0.5080 & 0.19774 & \\
\hline
\end{tabular}

- $\mathrm{P}<0.001$ showing statistically significant effect of improvement of vision after laser for diabetic macular edema

- $\mathrm{P}=0.960$ showing statistically non-significant difference between two groups

\section{Central macular thickness (CMT )}

Central macular thickness of the patients was measured pre-laser and in the follow up periods of one week, one month, three months. The mean preoperative CMT in Group A was 375.92 $\pm 65.69 \mathrm{um}$ and in Group B was $361.0 \pm 50.400 \mathrm{um}$. The mean CMT three months post-laser in Group A was $314.44 \pm 85.938$ um and in Group B was $0322.668 \pm 57.500$ um.

Table 4

Table showing change in mean CMT in different follow up periods

\begin{tabular}{lllccc}
\hline Period & N & Group & mean & SD & P value \\
\hline Pre-laser & 25 & Group A & 375.9200 & 65.69622 & 0.372 \\
& 25 & Group B & 361.0000 & 50.40089 & \\
One week & 25 & Group A & 360.0400 & 61.62892 & 0.492 \\
post laser & 25 & Group B & 349.2000 & 48.36493 & \\
One month & 25 & Group A & 338.1200 & 65.70345 & 0.488 \\
post laser & 25 & Group B & 327.2000 & 42.10800 & \\
Three months & 25 & Group A & 314.4400 & 85.93849 & 0.692 \\
post laser & 25 & Group B & 322.6800 & 57.50052 & \\
\hline
\end{tabular}

- $\mathrm{P}<0.001$ showing statistically significant effect of laser in improvement of central macular thickness for diabetic macular edema

- $\mathrm{P}=0.121$ showing statistically non-significant difference between two groups.

\section{Intraocular pressure (IOP)}

Intraocular pressure of the patients was measured pre-laser and in the follow up periods of 1week, one month, three months. The mean preoperative IOP in Group A was $16.32 \pm 3.912 \mathrm{mmhg}$ and in Group B was $15.84 \pm 3.923$ mmhg. The mean IOP 3 months post-laser in Group A was $16.88 \pm 3.67786 \mathrm{mmhg}$ and in Group B was $15.76 \pm 3.778 \mathrm{mmhg}$.

Table 5

Table showing change in mean IOP in different follow up periods

\begin{tabular}{lclccc}
\hline Period & N & Group & Mean & SD & P value \\
\hline Pre-laser & 25 & Group A & 16.3200 & 3.91280 & 0.667 \\
& 25 & Group B & 15.8400 & 3.92301 & \\
One week & 25 & Group A & 16.7200 & 3.75855 & 0.293 \\
post laser & 25 & Group B & 17.8400 & 3.69324 & \\
One month & 25 & Group A & 16.7200 & 3.75855 & 0.738 \\
post laser & 25 & Group B & 16.4000 & 2.90115 & \\
Three months & 25 & Group A & 16.8800 & 3.67786 & 0.294 \\
post laser & 25 & Group B & 15.76 & 3.78 & \\
& & & & & \\
\end{tabular}


- $\mathrm{P}=0.144$ showing statistically insignificant effect of laser in intraocular pressure for diabetic macular edema

- $\mathrm{P}=0.200$ showing statistically non-significant difference between two groups.

\section{Laser parameters}

For group A underwent modified grid laser with conventional laser. mean power of $100 \mathrm{~mW} \pm 19.4$, spot size $50-100 \mathrm{~mm}$ and burn duration of 50-100 ms. The mean number of burns was $80 \pm 7.4$

For group B underwent modified grid laser using pattern scan laser, mean power of $155 \mathrm{~mW} \pm 90.1$, spot size $50-100 \mathrm{~mm}$ and burn duration of 10-20 ms. the mean number of burns was $150 \pm 88.3$.

Table 6

Table showing different power and number of burns used in two groups

\begin{tabular}{lllll}
\hline Parameters & Group & mean & SD & P value \\
\hline Laser power & Group A & 100 & 19.4 & $<0.001$ \\
& Group B & 155 & 90.1 & \\
\multirow{2}{*}{ Number of burns } & Group A & 80 & 7.4 & $<0.001$ \\
& Group B & 150 & 88.3 & \\
\hline
\end{tabular}

- $\mathrm{P}<0.001$ showing statistically significant higher power and number of burns used in the pattern scan than in the conventional laser.

\section{5.-t Time}

For Group A underwent modified grid laser with conventional laser the mean treatment time was 10.02 mins \pm 2.21

For Group B underwent modified grid laser using pattern scan laser, the mean treatment time was 2.55 mins \pm 1.32

- $\mathrm{P}<0.001$ showing statistically significant difference in time between two groups. Pattern scan laser using less time than laser to produce the same effect.

\section{5-6. Others}

In Group A, three patients had no improvement in the macular edema and visual acuity and two cases worsened and the five cases required intravitreal injection.

In Group B, three patients had no improvement in the macular edema and visual acuity which required triamcinolone injection.

No complications related to laser treatment were noted in any patient. No effects were observed on blood vessels if the array inadvertently involved a retinal area traversed by blood vessels.

\section{Discussion}

Diabetic macular edema (DME) is a leading cause of blindness. The prevalence of DME is likely to increase with more people suffering from diabetes (Chen et al., 2010). There is good evidence that progression to DME is associated with duration of disease and poor glycemic control (Wong et al., 2009).

The Early Treatment of Diabetic Retinopathy Study (ETDRS) ${ }^{(2)}$ established macular photocoagulation as the standard care for diabetic clinically significant macular edema (CSME). Laser therapy reduced the risk of moderate visual loss secondary to diabetic CSME by $50 \%$.

Although the studies have helped place the anti-VEGF agents in pole position, the repeated number of injections, investigations and hospital visits place too high burden on the patient and the physician alike. This lack of a "finite therapy " has led to resurgence of novel laser therapies. Pattern scan laser and sub threshold micropulse laser has been hailed as an alternative to conventional laser in achieving the beneficial effect while minimizing the harmful effects. ${ }^{(11)}$
Regarding the laser power used, For group A underwent modified grid laser with conventional argon laser. mean power of $100 \mathrm{~mW} \pm 19.4$, spot size $50-100 \mathrm{~mm}$ and burn duration of $50-100$ ms. The mean number of burns was $80 \pm 7.4$ and For Group B underwent modified grid laser using pattern scan laser the power we used was higher, mean power of $155 \mathrm{~mW} \pm 90.1$, spot size $50-100 \mathrm{~mm}$ and burn duration of 10-20 ms. The mean number of burns was $150 \pm 88.3$.

Our study was comparable to another study made by Sal$\operatorname{man}^{(10)}$, which was a prospective randomized case series study

But the difference was in that the comparison was not only in modified grid laser but also in panretinal photocoagulation. As our study Both procedures had successful outcomes and also significantly higher powers were required with the Pascal (145 $\mathrm{mW})$ than with conventional laser groups $(100 \mathrm{~mW})(\mathrm{p}<0.001)$ in eyes that underwent focal/modified grid macular treatment with both systems.

Another pilot study done by (Sanghvi et al, 2008) testing the pascal photocoagulator on 26 eyes performing either focal of modified grid laser significantly higher powers were used for Pascal $(143 \mathrm{mw})$ than conventional $(100 \mathrm{mw})(\mathrm{p}<0.001)$ treatment.

To see if we can use the same parameters in both multisport laser and conventional argon laser (Aimee V. Chappelow et al., 2012 ) investigated that with newly diagnosed high-risk PDR which was treated with pan retinal photocoagulation (PRP) using either argon green laser or PASCAL,Patients treated with the PASCAL and argon laser received a similar number of spots (1438 vs $1386 ; \mathrm{P}=.59$ ). Patients treated with the PASCAL were more likely to experience persistence or recurrence of neovascularization within 6 months of initial treatment (73\% vs. $34 \%$; $>$ $.0008)$, this concluded that when using the pattern scan laser the treatment parameters should be changed to produce the same effect as the conventional argon laser.

In this study, though they did not specifically measure retinal lesion size, they deduced that the total area of PRP scars in the argon-treated patient exceeds that of the PASCAL-treated patient The increased rate of neovascularization recurrence experienced in the PASCAL-treated patients (vs argon-treated patients) suggests that given an equivalent number of treatment spots, the smaller total burn area created by the PASCAL compared to the argon laser results in a significant decrease in efficacy. Either additional lesions or larger spot sizes may be required to achieve comparable efficacy with the PASCAL compared to traditional argon green laser.

The efficacy of the multispot laser can be identified through the improvement of the VA and CMT. For the BCVA improvement, our study was comparable to study done by (Dimple et al., 2009) On 28 eyes of 17 patients. These 28 eyes were divided into two groups, group 1 underwent macular grid laser and group 2 underwent panretinal photocoagulation using the pattern scan laser (PASCAL). BCVA was stable or better in 66\% (14/21). In our study the mean preoperative BCVA in group B using the multispot laser changed from $0.3040 \pm 0.2140$ to $0.5080 \pm 0.1977$ 3 months post-laser.

Also, ( Jain et al., 2010 ) conducted a consecutive retrospective analysis To evaluate the visual acuity (VA) and optical coherence tomography thickness results of short-duration pattern scanning laser macular photocoagulation in the treatment of clinically significant macular edema because of diabetes. The patients were treated with the same pattern scan laser unit. There was an average improvement in VA of $0.060 \log$ MAR (an improvement from 20/45 to 20/40, or approximately 3 Early Treatment Diabetic 
Retinopathy Study letters; $\mathrm{P}=0.0007$ ).

Comparable results were found by (Sanghvi et al, 2008) from the 26 patients all had improvement of the BCVA from $0.31 \pm 0.23$ to $0.30 \pm 0.27$ except two case who had no improvement.

To compare effect of both lasers on BCVA, both cause improvement in the BCVA. visual acuity improved from 0.294 \pm 0.1715 in group A and $0.3040 \pm 0.2140$ in group B pre-laser to $0.4820 \pm 0.244$ in group A and $0.5080 \pm 0.1977$ in group B 3 months after laser .

In Salman study ${ }^{(10)}$, the BCVA improved in group that used the conventional laser from 0.30 LOGMAR to 0.22 LOGMAR, and in the group used pattern laser improved from 0.30 LOGMAR to 0.25 LOGMAR .

For the improvement of macular thickness, (Dimple et al., 2009) the average central foveal thickness on ocular coherence tomography improved in $71 \%$ (15/21) which agreed with our study as the mean preoperative CMT in group A decreased from $375.92 \pm 65.69$ um in group A and 361.0 \pm 50.400 um in group B to be $314.44 \pm 85.938 \mathrm{um}$ in Group A and $322.668 \pm 57.500 \mathrm{um}$ in Group B which is a good successful outcome.

Also the effectiveness of the multipot laser was revealed in (Jain et al., 2010) study a reduction of central optical coherence tomographic thickness of $40 \mu \mathrm{m}$ and $37 \mu \mathrm{m}$ (spectral domain and time domain optical coherence tomography groups, respectively), both of which were statistically significant $(\mathrm{P}=0.0049$ and 0.012 , respectively).

The time element of treatment is also important for both patient and doctor. Using the multispot laser shorten the treatment time of the patient with the same therapeutic effect. In this concern another randomized clinical trial was made by Mugit et al., ${ }^{(17)}$ to investigate the effects of pattern scanning laser multispot pan retinal photocoagulation given in a single-session (SS-PRP) vs. single-spot multiple-session PRP (MS-PRP) on proliferative diabetic retinopathy. A positive effect on PDR was observed in $74 \%$ of eyes in the SS-PRP group vs 53\% in the MS-PRP group (P $=.31$ ). There were no significant difference between two groups in terms of visual acuity improvement but Mean treatment time for SS-PRP was 5.04 minutes (SD, 1.5 minutes) compared with 59.3 (SD, 12.7 minutes) in the MS-PRP group $(\mathrm{P}<0.001)$. This means that the treatment time decreased using the multispot laser but producing the same therapeutic effect.

These results agreed with our study as, for Group A underwent modified grid laser with conventional laser. Mean treatment time was 10.02 mins \pm 2.21 and For Group B underwent modified grid laser using pattern scan laser, the mean treatment time was 2.55 mins \pm 1.32 , this means that the treatment time of multispot laser is shorter but as effective as conventional argon laser.

The higher power levels required with the multispot system did not result in any complications. This may be a reflection of the reduced laser energy per burn reaching the eye secondary to its shorter duration. Fluence is calculated as (power X time /area), and provided that spot size remains unchanged, with a burn duration of $20 \mathrm{~ms}$ the fluence is less than with a $100 \mathrm{~ms}$ burn when titrating to the same burn intensity because of reduced diffusion of heat(bailey et al,199912)

It is this thermal effect that produces therapeutically desirable retinal lesions. In histopathological study (Blumenkranz et al., 20064) using pulse durations of $20 \mathrm{~ms}$, the threshold for a visible burn was 110-120 $\mathrm{mW}$, while that for retinal hemorrhage was 600
$\mathrm{mW}$, suggesting an adequate safety margin. Another recent study eyes has demonstrated that $20 \mathrm{~ms}$ pulse durations represent an optimal compromise between reduced collateral damage and sufficient width of the therapeutic window.(Blumenkranz et al., 20064) In our study, we found good safety of Pattern scan laser as there were no intra or postoperative complications in 3 months follow up periods.

In (Dimple et al., 2009) study group 1 underwent macular grid laser and group 2 underwent panretinal photocoagulation using the pattern scan laser (PASCAL), group 1 they have not noted any related complications. In group 2, the neovascularization regressed at least partially in $3 / 7$ patients.

In Salman studies ${ }^{(10)}$, No complications related to laser treatment were noted in any patient. No effects were observed on blood vessels if the array inadvertently involved a retinal area traversed by blood vessels. None of the patients experienced bleeding of either retinal or choroidal origin. No effects were observed due to the doctor being unable to avoid old laser burns in re-treatments.

The limitations of our study were the low number of patients and the short follow up period. More studies are needed in large scale of patients for better evaluation of the efficacy of both types of laser and prolonged follow up periods up to 1 year.

Other limitation was that we should use it in PRP rather than grid or focal laser, so that the time element difference between the two types of lasers would be more obvious.

\section{REFERENCES}

1. Roider J, Brinkmann R., Wirbelauer C, et al., Subthreshold (retinal pigment epithelium) photocoagulation in macular diseases: a pilot study. Br. J. Ophthalmol. , 2000; 84, 40-47

2. Early Treatment Diabetic Retinopathy Study Research Group. Photocoagulation for diabetic macular edema. ETDRS report no.1. Arch Ophthalmol 1985; 103:1796-806.

3. Guigou S, Multispot laser photocoagulation,Retina Today,2014:1.

4. Blumenkranz MS, Yellachich D, Andersen DE, Wiltberger MW, et al. Semiautomated patterned scanning laser for retinal photocoagulation. Retina. 2006; 26:370-6.

5. Nagpal M: Clinical experience with a high-speed multispot laser. Retina Today, 2008.

6. Muqit MM, Marcellino GR, Henson DB, Young LP, et al. Pascal panretinal laser ablation and regression analysis in proliferative diabetic retinopathy: Manchester Pascal Study Report 4. Eye (Lond). 2011 25(11):1447-56.

7. Vogel, A., Lauterborn, W., 1988. Acoustic transient generation by laser-produced cavitation bubbles near solid boundaries. J. Acoust. Soc. Am. 84, 719-731.

8. Brinkmann, R., Huettmann, G., Rogener J., et al. Origin of retinal pigment epithelium cell damage by pulsed laser irradiance in the nanosecond to microsecond time regimen. Lasers Surg. Med. 2000, 2: 451-464.

9. Roegener, J., Brinkmann, R., Lin, C.P., Pump-probe detection of laser-induced microbubble formation in retinal pigment epithelium cells. J. Biomed. Opt. 2004. 9, 367-71.

10. Salman AG, Pascal laser versus conventional laser for treatment of diabetic retinopathy, Saudi journal of ophthalmology, 2011:5.

11. Kwasniewska FS,. Lasers in Ophthalmology: Basic, Diagnostic, and Surgical Aspects. The Hague, the Netherlands: Kugler Publication; 2003. p. 175.

12. Bailey CC, sparrow JM, Grey RH et al.: The national diabetic retinopathy laser treatment audit III. Clinical outcomes, Eye 1999 13, 151-59. 
13. Mainster,M.A, Sliney,D.H, Bachler III,C.D,et al., Laser photo distriputers:damage mechanisms, instrument design and safety. ophthalmology 1983; 90, 973-91.

14. Sheuele,G.,Rumohr,M.,Huettmann.G.,et al. RPE damage thresholds and mechanisms for laser exposure in the microsecond to- millisecond time regimen .invest.ophthalmol Vis.sci,2005;46,714.

15. Sliney, D.H., Marshall, J., Tissue specific damage to the retinal pigment epithelium: mechanisms and therapeutic implications.Lasers Light Ophthalmol. 1992; 5, 17-28.

16. Aimee v chappelow, kevin tan, nadia k waheed, peter k. Kaiser ; Panretinal Photocoagulation for Proliferative Diabetic Retinopathy: Pattern Scan Laser Versus Argon Laser. American journal of ophthalmology January 2012, 137-42.e2.
17. Muqit MM, Gray JC, Marcellino GR, Henson DB, Young LB, Patton $\mathrm{N}$, et al. In vivo laser-tissue interactions and healing responses from 20- vs 100-millisecond pulse Pascal photocoagulation burns. Arch Ophthalmol. 2010; 128:448-55.

18. Dimple Modi,Paulpoj Chiranad ,Levent Akduman .Efficacy of patterned scan laser in treatment of macular edema and retinal neovascularization .Clinical ophthalmology .2009:3 , 465-470

\section{Corresponding Author:}

Kareen Mohsen Elsawah

e-mail: drkareemelsawah@gmail.com 